\title{
HaCIA UN NUEVO CÓDIGO DE NOMENCLATURA BIOLÓGICA:
}

\section{EL BIOCÓDIGO}

\author{
Victoria Sosa, José A. Guerrero, Álvaro Flores-Castorena, \\ Domitila Martínez-Alvarado, Raúl Acevedo-Rosas y \\ Carlos Aguilar-Ortigoza
}

División de Posgrado. Instituto de Ecología, A.C.

Apartado Postal 63, 91000 Xalapa, Veracruz, México.

\begin{abstract}
Resumen. Desde 1991 existe la propuesta de que la nomenclatura biológica sea reglamentada por un solo código, el biocódigo, el cual sustituiría a los cinco códigos vigentes: botánica, plantas cultivadas, zoología, bacteriología y virus. Se ha planteado por la necesidad de que exista una sola base reguladora, simple y compatible con la nomenclatura biológica para cumplir sus objetivos que son claridad, uniformidad y estabilidad de los nombres científicos. En esta revisión se indican los cambios en las reglas de nomenclatura que, de ser aprobado el biocódigo, tendrían que aceptar los taxónomos vegetales. Asimismo se presenta la controversia que ha generado este nuevo código entre la comunidad de taxónomos vegetales. Entre los cambios más importantes se encuentran el abandono del latín para las diagnosis de nuevos taxa, la creación de una dependencia que se encargue del registro de los nombres científicos, el uso de una nueva terminología nomenclatorial y un gran número de homónimos al incluir los nombres científicos de los todos organismos del planeta. Palabras clave: nomenclatura biológica, Código Internacional de Nomenclatura Botánica, biocódigo, Código de Nomenclatura Biológica

Abstract. In 1991 a proposal to establish a new code of biological nomenclature (BioCode) which would have preeminence over existing codes of nomenclature for virology, bacteriology, botany and zoology, was presented. The BioCode was proposed to prescribe universal nomenclature terminology and to resolve conflicts among the existing codes. This paper compares the main rules of the botanical, zoological and the bionomenclature codes. It discusses the main changes of nomenclature rules that plant taxonomists would have to accept if the BioCode is approved. It also presents the controversy among different groups of plant taxonomists regarding several articles of the BioCode. Most controversial changes proposed by the BioCode are: abandon of Latin for diagnoses, mandatory registration of new names, new nomenclature terminology, authority and homonyms.
\end{abstract}

Key words: biological nomenclature, International Code of Botanical Nomenclature, Biocode, bionomenclature

a nomenclatura biológica, es decir, los principios y procedimientos que gobiernan el establecimiento de los nombres científicos de los organismos es vital para la comunicación científica. En la actualidad es muy importante que los nombres científicos estén disponibles para el conocimiento de la biodiversidad mundial (McNeill, 1996a).

Los principios y procedimientos están contenidos en diferentes códigos de nomenclatura para los diversos grupos de organismos. Actualmente existen cinco códigos de nomenclatura: el Código Internacional de Nomenclatura Botánica (Greuter et al., 1995), el Código Internacional de Plantas Cultivadas (Trehane et al., 1995), el Código Internacional de Nomenclatura Zoológica (Ride et al., 1985), el Código Bacteriológico (Lapage et al., 1992) y el Código Internacional de Clasificación y Nomenclatura de Virus, que apenas se encuentra como una propuesta, desarrollada a partir de las Reglas de la Nomenclatura y Clasificación de Virus (Murphy et al., 1995). 
Sin embargo, desde 1991 se ha propuesto que la totalidad de la nomenclatura biológica sea regulada por un único código nuevo, el biocódigo, con base en la necesidad de que exista una sola base reguladora, simple y compatible con la nomenclatura biológica cumpliendo sus objetivos que son claridad, uniformidad y estabilidad de los nombres científicos (McNeill, 1996a).

Inicialmente se había propuesto que el biocódigo, de ser sancionado, estuviera vigente a partir del año 2 000. Sin embargo, su evaluación y aprobación por las sociedades científicas relacionadas con los diferentes códigos de nomenclatura ha tomado más tiempo. Se había planteado que durante la "Sección de Nomenclatura" del xvi Congreso Internacional de Botánica (del 26 al 30 de julio de 1999, en St. Louis, Missouri) se propondría la aprobación del biocódigo. Recientemente, se notificó que aún no será evaluado el biocódigo, sino que se presentarán, entre otras, propuestas sobre el registro obligatorio de nuevos nombres científicos (Greuter y Hawksworth, 1999).

Esta revisión tiene como objetivos comparar las principales reglas de nomenclatura botánica y zoológica en base a los códigos de nomenclatura vigentes; presentar los cambios que tendrían que aceptar los taxónomos vegetales si el biocódigo es establecido, así como presentar un panorama actual de la controversia que el biocódigo ha suscitado entre diferentes grupos de taxónomos vegetales.

\section{El Código Internacional de Nomenclatura Botánica}

La historia de los códigos botánicos es larga y la reglamentación ha sufrido numerosos cambios (ver Nicolson, 1991 donde presenta una amplia literatura sobre nomenclatura botánica). Los precursores de la nomenclatura botánica son Alfonso de Candolle y Agustín Píramo de Candolle. En la preparación de la "Teoría elemental de la botánica" y en el "Prodromous" respectivamente, aplicaron ya conceptos sobre prioridad de publicación, epíteto, homónimo, tautónimo y "nomen nudum", manteniendo el uso de nombres propuesto por Linneo (Nicolson, 1991; Greuter, 1998a).

El primer Código Internacional de Nomenclatura Botánica (CINB) fue el de París (Anónimo, 1867) en el que se formularon las primeras reglas que debían seguir los taxónomos para proponer nombres científicos. Estuvo basado en gran medida en las obras de Linneo $(1753,1754,1764)$, quien estableció que los nombres científicos fueran binominales. Desde este primer código se determinó el principio de prioridad cronológica, es decir; que el primer nombre publicado es el que tiene prioridad, y la publicación válida de los nombres. Se utilizó el latín tanto en la formación de nombres como en la diagnosis de nuevos taxa.
En 1930, se estableció un código de nomenclatura botánica universal en el congreso internacional de botánica de Cambridge. Cada seis años se organiza un congreso internacional de botánica en el que se dedica una sección a la nomenclatura, en la semana previa a los congresos. Obviamente esto ha hecho que el CINB haya evolucionado, que haya alcanzado una gran complejidad hasta convertirse en un documento jurídico y que exista un grupo de taxónomos expertos en nomenclatura, muchos de los cuales forman parte de la comisión de nomenclatura (International Bureau for Plant Taxonomy and Nomenclature).

El CINB es coordinado y publicado por la Asociación Internacional de Taxonomía Vegetal (International Association for Plant Taxonomy, IAPT). La IAPT constituye la sección de Taxonomía Vegetal de la Unión Internacional de Ciencias Biológicas (International Union of Biological Sciences, IUBS). El CINB más reciente es el del congreso de Tokio de 1994 (Greuter et al., 1995) que es el que está en vigor. Lo relacionado con la nomenclatura botánica se publica en la revista Taxon, órgano oficial de la IAPT. Cualquier cambio o enmienda a las reglas de nomenclatura es propuesto en Taxon y aprobado en una sección de nomenclatura de cada congreso internacional de botánica. Cada miembro personal de la IAPT puede participar con un voto preliminar por correo, sobre las propuestas de nomenclatura. Los votos institucionales no son permitidos por correo. Los autores que propusieron las enmiendas y los miembros permanentes de los comités de nomenclatura también pueden votar: Los miembros de la IAPT presentes en la sección de nomenclatura, los asistentes registrados en las sesiones de nomenclatura de los congresos internacionales y los representantes de los herbarios reconocidos por la comisión de nomenclatura de los congresos internacionales de botánica cuentan con voto sobre estos cambios. Los votos personales no pueden ser transferidos ni acumulados. Un miembro de la sección de nomenclatura puede ser el delegado oficial de más de un herbario, aunque no se permite que una persona tenga más de 15 votos, incluyendo su propio voto personal (Greuter y Hawksworth, 1999).

El CINB esta formado por 62 artículos, con apéndices y listas complementarias (tabla 1; se encuentra en línea para ser consultado: http://www.bgbm.fuberlin.de/iapt/nomenclature/code/default.htm). Cada artículo suele tener además una serie de recomendaciones y con frecuencia presenta varios ejemplos. También incluyen notas explicativas aunque la única parte válida es el enunciado. En la mayor parte de los casos, su aplicación es sencilla. Sin embargo, puede complicarse si se toman en cuenta los antecedentes históricos, ya que en la evolución del 
CINB se han cambiado algunas reglas y existen excepciones en la aplicación de la retroactividad. En estos casos es aconsejable la consulta a uno de los especialistas en nomenclatura botánica.

Los seis principios básicos del CINB son: 1] la nomenclatura botánica es independiente de la zoológica y bacteriológica. El Código se aplica igualmente a nombres de grupos taxonómicos tratados como plantas, no importando si estos grupos fueron originalmente considerados así; 2] la aplicación de grupos taxonómicos se determina por tipos nomenclatoria- les, es decir, un ejemplar establecido que está ligado al nombre; 3] el nombre científico con prioridad es el primero en términos cronológicos; 4] cada grupo taxonómico dentro de su circunscripción, posición y rango puede tener un solo nombre correcto, el primero de acuerdo con las reglas, excepto en casos específicos; 5] los nombres científicos de grupos taxonómicos se tratan como latinos independientemente de su derivación y 6] las reglas de nomenclatura son retroactivas a menos de que se indique lo contrario.

Tabla 1. Principales divisiones y capítulos del Código Internacional de Botánica de Tokio, que está actualmente vigente (Greuter et al. 1995).

División I

Principios

División II

Reglas y recomendaciones

Capítulo I Rangos de los taxa (Art. 1, 2, 3, 4, 5)

Capítulo II Nombres de taxa (provisiones generales)

Sección 1 Definiciones (Art. 6)

Sección 2 Tipificación (Art. 7, 8, 9, 10)

Sección 3 Prioridad (Art. 11 y 12)

Sección 4 Limitación del principio de prioridad (Art. 13, 14, 15)

Capítulo III Nomenclatura de taxa de acuerdo a su rango

Sección 1 Nombres de taxa por arriba del rango de familia (Art. 16, 17)

Sección 2 Nombres de familias y subfamilias, tribus y subtribus (Art. 18, 19)

Sección 3 Nombres de géneros y subdivisiones de géneros (Art. 20, 21, 22)

Sección 4 Nombres de especies (Art. 23)

Sección 5 Nombres de taxa por debajo del rango de especie (taxa infraespecífos) (Art. 24, 25, 26, 27)

Sección 6 Nombres de plantas en cultivo (Art. 28)

Capítulo IV Publicación efectiva y válida

Sección 1 Condiciones y fechas de publicación efectiva (Art. 29, 30, 31)

Sección 2 Condiciones y fechas de la publicación válida de los nombres

(Art. 32, 33, 34, 35, 36, 37, 38, 39, 40, 41, 42, 43, 44, 45)

Sección 3 Citas de autores, nombres para propósitos de precisión (Art. 46, 47, 48, 49, 50)

Sección 4 Recomendaciones generales de citación (Rec. 50A-F)

Capítulo $\vee$ Rechazo de nombres (Art. 51, 52, 53, 54, 55, 56, 57, 58)

Capítulo VI Nombres de hongos con un ciclo de vida pleomórfico (Art. 59)

Capítulo VII Ortografía de nombres y epítetos y género de nombres génericos

Sección 1 Ortografía de nombres y epítetos (Art. 60 y 61)

Sección 2 Género de nombres genéricos (Art. 62)

División III Previsiones para la modificación del Código

Apéndice I Nombres de híbridos (Art. H.1, H.2, H.3, H.4, H.5, H.6, H.7, H.8, H.9, H.10, H.11, H.12)

Apéndice IIA Nomina familiarum algarum, fungorum et pteridophytorum conservanda et rejicienda

Apéndice IIB Nomina familiarum bryophytorum et spermatophytorum conservanda

Apéndice IIIA Nomina generica conservanda et rejicienda

Apéndice IIIB Nomina specifica conservanda et rejicienda

Apéndice IV Nomina utique rejicienda (B. Fungi, C. Bryophyta, E. Spermatophyta)

Apéndice $V$ Opera utique oppressa 
Tabla 3. Principales direcciones electrónicas de organizaciones relacionadas con la nomenclatura botánica y biológica.

American Society of Plant Taxonomists

http://www.sysbot.org/

BioCode (1997)

http://www.rom.on.ca/biodiversity/biocode/biocode1997.html

Biodiversity and Biological Collections Web Server

http://www.biodiversity.uno.edu/

Biological Nomenclature Proceedings

http://www.life.umd.edu/bees/96sym.html

Gray Herbarium Card Index

http://herbaria.harvard.edu/Data/Gray/search.html

Index Herbariorum

http://www.nybg.org/bsci/ih/ih.html

Index Nominum Genericorum (Plantarum)

http://www.nmnh.si.edu/ing/

International Association for Plant Taxonomy

http://www.bgbm.fu-berlin.de/iapt/

International Association for Plant Taxonomy Alternative Website

http://mason.gmu.edu/ ckelloff/vfunk/index.html

International Committee on Bionomenclature

http://www.rom.on.ca/biodiversity/biocode/bioicb1997.html

International Union for Biological Sciences Taxonomic Database Working Group (TDWG)

http://www.tdwg.org/

Missouri Botanic Garden: Registration of Plant Names

http://www.mobot.org/MOBOT/research/registr.html

Taxacom: Biological Systematics and Biocollections Computerization Discussion List

http://www.biodiversity.uno.edu/mail_archives/taxacom/

XVI International Botanical Congress

http://www.ibc99.org/

El método de tipificación es quizá de los más importantes para el CINB. Cada nombre debe estar ligado con un ejemplar tipo. En la práctica, las descripciones de un taxón nuevo exigen la indicación del ejemplar tipo. En segundo término de importancia está el principio de prioridad. El año de 1753, fecha de la publicación de "Species Plantarum" de Linneo es la fecha que se toma en cuenta como punto de partida para los nombres publicados. Los nombres anteriores a esta fecha se tienen que sancionar pos- teriormente. La aplicación estricta del principio de prioridad y de las reglas para otorgar nombres han causado problemas. Para afrontar estos problemas y excepciones al código, se publican los "Nomina Conservanda" en la revista Taxon. Se envía una solicitud de conservación de un nombre a esta revista y en la próxima sección de nomenclatura del correspondiente congreso internacional de botánica se somete. Si es aceptado el nombre se publica como un apéndice al CINB. 
La formación de nombres de taxa va de acuerdo con su categoría. Los nombres de nivel de familia hacia abajo son obligatorios y se rigen por principios de prioridad y tipificación. Los nombres de géneros y de especies pueden derivarse o crearse de acuerdo con el criterio del autor. Sin embargo, deben seguir las reglas de la gramática latina, por lo que deben tener género gramatical, terminaciones y declinaciones concordantes. Los tautónimos no son aceptados.

En las publicaciones científicas botánicas después del género y especie se cita al autor que por primera vez describió la especie. El nombre puede escribirse en extenso o abreviado. Existen varias obras que listan las abreviaturas de los autores (e.g. Brummitt y Powell, 1992).

\section{El contraste entre dos Códigos, el de Botánica y el de Zoología}

Pese a que ambos códigos se basan en los mismos principios: que exista un solo nombre para cada taxón y que la elección de diferentes nombres se base en la precedencia cronológica, algunas de sus principales reglas son diferentes.

El CINB y el Código Internacional de Nomenclatura Zoológica (CINZ) han divergido en forma significativa desde hace más de 100 años (Hawkswoth, 1995). Así, en muchas ocasiones se han usado diferentes términos esencialmente para el mismo concepto. Por ejemplo, el CINB distingue entre sinónimos nomenclatoriales y taxonómicos, mientras que el CINZ utiliza sinónimos objetivos y subjetivos. Más complicadas aún son las situaciones en que el mismo término se usa para diferentes conceptos. Los casos más notables son el uso de la palabra "válido", la cual en el CINB se usa para hacer referencia a un nombre que es "válidamente publicado", un concepto para el cual el Cinz usa la palabra "disponible". Para los zoólogos "válido" significa lo que los botánicos llaman nombre "correcto", es decir, el nombre que debe usarse dado un tratamiento taxonómico particular (McNei1l, 1996b). La tabla 2 muestra los términos usados por los CINB, CINZ y el Biocódigo.

En el CINZ, con respecto al principio de prioridad, los epítetos tienen prioridad (y son automáticamente generados) en varios rangos taxonómicos simultáneamente (familia, género y especie). En contraste, en el CINB sólo tienen prioridad en un solo rango taxonómico, en el que fueron descritos. En el cINZ, los nombres científicos deben tratarse como latinos independientemente de su origen, no obstante, el epíteto específico no necesariamente debe de conformarse al masculino, femenino o neutro del género. En el CINB debe seguirse la gramática latina en la formación de nombres. En el cinz, la cita de los autores de cada especie es opcional, es decir; pueden o no citarse cuando se hace referencia a una especie, mientras que para el CinB sí se incluye en el nombre científico el del autor. En el CINZ, para el establecimiento de nuevos nombres, las descripciones pueden hacerse en cualquier idioma de alfabeto occidental y deben publicarse en medios impresos y a partir de 1998 éstos pueden publicarse en medios electrónicos, siempre que se depositen hojas impresas en diez bibliotecas públicas. En el CINB los nombres obligatoriamente deben publicarse un medio impreso de amplia difusión con su diagnosis en latín. En el CINZ, las especies descritas como nuevas deben de notificarse al Zoological Records a más tardar cinco años después de su publicación. En el CiNB sólo se exige que los nombres hayan sido válidamente publicados, sin que sea necesario un registro (Ride et al., 1985).

\section{El biocódigo}

En la asamblea general de la IUBS reunida en Amsterdam en 1991, se aprobó una resolución para promover la armonización de los diferentes códigos de nomenclatura biológica. Posteriormente, en 1994, se llevó a cabo una reunión exploratoria en Inglaterra, con representantes de los cuatro códigos existentes y el de plantas cultivadas, produciendo un reporte en el que se propone un Código Armonizado de Bionomenclatura para todos los seres vivientes del planeta (IUBS 1994a), así como un glosario de términos utilizados en la bionomenclatura (IUBS 1994b). Se estableció un Comité Internacional de Bionomenclatura (CIB) en conjunto con la IUBS y la Unión Internacional de Sociedades Microbiológicas (IUMS) en 1995, para promover este trabajo de armonización. El Comité quedó integrado por dos representantes del código botánico, dos del código zoológico y un representante del de plantas cultivadas y otro de virus. Desde entonces, el comité ha promovido diversas reuniones y ha asistido a congresos científicos para promover el biocódigo (Reveal, 1996).

La aceptación del biocódligo por los botánicos, dependerá de su aprobación en la Sección de Nomenclatura de un congreso internacional de botánica. Inicialmente se había planteado que su aprobación sería en el XVI Congreso Internacional de Botánica. Sin embargo, se ha pospuesto esta propuesta para la primera década del año 2 000. La Comisión de Nomenclatura Zoológica y el Comité Internacional de Bacteriología Sistemática también tendrán que aprobar el biocódligo.

La discusión que se está generando en las diferentes sociedades y grupos de taxónomos alrededor del bio- 
Tabla 2. Equivalencias de los términos nomenclatoriales y de las principales reglas propuestos en el Biocódigo con los códigos de botánica y zoología vigentes. Los conceptos de los términos dados como equivalentes no son exactamente los mismos ( por ejemplo superfluidad nomenclatorial, un obstáculo a la legitimación para el CINB no se conoce para el CINZ) (Con base en Greuter et al. 1998) (CINB= Código Internacional de Nomenclatura Botánica, CINZ= Código Internacional de Nomenclatura Zoológica).

\section{Biocódigo}

Publicación y fechas de publicación

Publicado

Registrado

Fecha

Prioridad

Precedencia

Primer nombre

Nombre posterior

Forma de publicación:

Impresa, microcarta,

microficha, disco láser

Estatus nomenclatorial

Establecido

Registrado

Aceptable

\section{Estatus taxonómico:}

Aceptado

Tipos de nombres:

Nombre que lleva

el tipo

Taxón nominal

\section{Sinonimia:}

Homotípico

Heterotípico

Nombre reemplazado

Idioma de las diagnosis:

Optativos: latín o inglés

\section{Principio de prioridad:}

Coordinado, prioridad simultánea

en rangos de especie, género y familia

Dejando de lado las reglas:

Conservado

Rechazado

Surpimido

\section{CINB}

Efectivamente

publicado

Fecha o

prioridad

Prioridad

Prioridad

Primero

Primero

Impresa en revista

científica

Válidamente
publicado
Registrado
Legítimo

Correcto

Tipo nomenclatorial

Nombre y tipo

Nomenclatorial

Taxonómico

Sustituto admitido

Latín obligatorio

Solo en el rango

taxónomico descrito

Conservado

Rechazado

Explícitamente

rechazado

\section{CINZ}

Publicado

Prioridad

Prioridad

Precedencia

Senior

Junior

Impresa o por medio

con 10 copias impresas

Disponible

Potencialmente

Válido

Válido

Nombre que lleva

el tipo

Taxón nominal

Objetivo

Subjetivo

Reemplazo

explícito

Cualquier idioma occidental

Prioridad simultánea en rangos de especie, género y familia

Conservado

Condicionalmente

suprimido

Suprimido 
código, está disponible en la Red Mundial de Información. Las principales páginas y direcciones se incluyen en la tabla 3.

El biocódigo contempla cambios substanciales, en comparación con los códigos existentes, sobre todo con el de botánica. Por ejemplo, algunos términos usados por los botánicos tales como "efectivamente publicado", "válidamente publicado", "legítimo" y "correcto", y algunos otros usados por los zoólogos tales como "disponible", "válido", "senior" y "junior" serán sustituidos por términos nuevos cuyo significado sea idéntico o por palabras de uso común (tabla 2) (Greuter et al., 1996).

En el biocódigo, los rangos taxonómicos van de reino a especie y cuando se requiere, se utilizan rangos secundarios como subespecie, variedad o forma, o si se requieren rangos adicionales se agrega el sufijo "super" o "sub"; por ejemplo superfamilia o subgénero. El estatus de los nombres será coordinado, es decir, los epítetos tendrán prioridad simultánea para los rangos de especie, género y familia. Las limitaciones de prioridad estarán basadas en "Listas de Nombres Aceptados o en Uso", por lo que los nuevos nombres tendrán que ser registrados y anexados a estas listas. Las descripciones o diagnosis de taxa nuevos podrán escribirse en latín o en inglés y las publicaciones de estos podrán hacerse en microcartas, microfichas y discos láser, pero no por distribución de películas o fotografías de texto o imágenes (Greuter et al., 1998).

En el biocódigo se menciona el registro de nuevos taxa mediante una dependencia creada para esto, siendo el día de publicación la fecha de registro. La tipificación de especies y taxa infraspecíficos se hará mediante un ejemplar. El tipo será un solo individuo o un mayor número cuando los organismos son pequeños, colectados en el mismo espacio y tiempo. Cuando no sea posible preservar un organismo (e.g. virus) el tipo podrá ser una ilustración o puede considerarse un ejemplar criopreservado. Los homónimos de familia, género y especie, a menos que sean conservados, serán inaceptables. El día de precedencia de taxa antes de la fecha de aprobación del biocódigo, será el aplicado en los códigos vigentes o en la lista de nombres protegidos; los propuestos después serán con base en el biocódigo. El principio de precedencia no es aplicable a taxa superiores al rango de familia. Los sinónimos basados en un solo tipo se llamarán sinónimos homotípicos y los basados en tipos diferentes serán heterotípicos. Los nombres de híbridos se designarán de acuerdo al apéndice del CINB. La ortografía de epítetos específicos se conservará. La cita del autor será semejante al CINB. Las autoridades del código serán la IUBS, IUMS y el CIB. En el caso de la transferencia de epítetos, la cita del autor que la hace será opcional. Para la formación de los nombres científicos el género gramatical de los nombres genéricos será abolido, por lo que al hacer transferencias de epítetos específicos se respetará la forma original del adjetivo. No se permitirán homonimias entre organismos de dos reinos distintos (Greuter et al., 1998).

\section{La controversia}

Los cambios propuestos por el biocódigo en comparación con el cINB están principalmente en relación con:

Terminología nueva. Un punto considerado fundamental en la creación del biocódigo es la adopción de una nueva terminología (resumida en la tabla 2). Los términos sobre la validación de la publicación y la legitimidad de los nombres, que cuentan con una larga historia en el CINB, tendrían que ser abandonados. Los taxónomos en favor del biocódigo afirman que esta terminología asegurará que se resuelva la ambigüedad y confusión surgida por el uso de los mismos términos para definir conceptos diferentes, favoreciendo de este modo a los usuarios del biocódigo (McNeill, 1996a). No obstante, los taxónomos que se oponen al biocódigo han señalado que la creación de términos nuevos resultará en una confusión mayor, ya que en adelante los botánicos y zoólogos tendrán que familiarzarse con dos terminologías en lugar de una (Brummitt, 1996; Orchard et al., 1996).

Registro de nombres y listas de nombres de uso actual. Otro punto central del biocódigo es que los nombres científicos de nuevos taxa tendrán que ser registrados ante una comisión expresamente creada para tal propósito e incluídos en listas de nombres de uso actual. La sustitución del principio de prioridad por las listas de nombres aceptados y por el registro de nombres válidos según opositores del biocódigo es impráctica, taxonómicamente peligrosa, consumidora de tiempo y costosa (Delprete, 1996). Afirman que el registro es taxonómicamente peligroso, pues los taxónomos dependerán de la comisión de registro para hacer válido el nombre científico y no solamente de los árbitros de la revista donde se haya publicado. Apuntan también que aún no se ha determinado el origen de los fondos que requeriría la comisión de registro de nombres a cargo de IUBS, ni los detalles de la operación del registro (Turland y Davidse, 1998). Una de las reglas más importantes en la nomenclatura botánica es que el único requisito para describir un nuevo taxón es publicarlo en cualquier medio impreso de amplia difusión. Su abolición implicaría hacer a un lado la historia según algunos taxónomos (e.g. Stro- 
ther, 1995). Otros taxónomos han indicado que el registro de nombres duplicaría la tarea de indexar nombres científicos ya desarollados por otras organizaciones como Index Kervensis y Gray Card Index (Turland y Davidse, 1998).

Los taxónomos que están de acuerdo con el registro de nombres científicos apuntan que muchas veces se tiene que invertir demasiado tiempo en revisar enormes cantidades de literatura de años, e incluso siglos anteriores, para conocer si un nombre científico ha sido establecido propiamente, llegando en algunas ocasiones a convertirse en un investigador de la historia más que en un científico (McNeill, 1996a; Wilson, 1997). Los taxónomos que favorecen el registro de nombres, han mencionado que muchos nombres tradicionalmente adscritos a un autor en una fecha, ya habían sido publicados por otro autor en una fecha anterior, y con frecuencia en una revista tan inconspicua, que a veces nunca ha sido consultada por los taxónomos (Zijlstra, 1996) y que este problema se resolvería con una lista única de nombres científicos.

Abandono del latin y formación de nombres cientificos. El biocódigo apunta que las diagnosis de nuevos taxa pueden ser en latín o en inglés. Este es otro punto de confrontación y quizá por la tradición botánica uno de los más difíciles de aprobar. Los taxónomos que se oponen a este cambio, han señalado que el uso del inglés es inaceptable ya que debido a que es una lengua "viva" es posible que su gramática cambie, lo cual acarrearía problemas de ambigüedad en el futuro; además, eso sería un privilegio para los países de habla inglesa (Filgueiras, 1997). Los que favorecen el abandono del latín han mencionado que cuando se originó la nomenclatura moderna el uso del latín se estableció no por ser una lengua "muerta" o neutral, sino por el hecho de que era el lenguaje culto y de la ciencia en el siglo xviII (McNeill, 1997). Unos cuantos botánicos han indicado que el uso del latín está dejando de ser una tradición útil, siendo actualmente tan solo un ritual sin sentido (Craven, 1997), y además que en ocasiones las descripciones en latín son tan malas en su gramática y sintaxis que sólo pueden ser descifradas o entendidas por su compositor (Barneby, 1990), por lo que resulta más práctico y lógico hacer descripciones que pudieran ser entendidas por la mayoría de los científicos (Greuter, 1996; McNeill, 1997).

Otro de los puntos propuestos en el biocódigo se refiere a la formación de los nombres científicos, en los que el género gramatical latino de los nombres genéricos será abolido, por lo que al hacer transferencias de epítetos específicos se respetará la forma original del adjetivo. Algunos botánicos han apunta- do que si existen reglas gramaticales claras y precisas, no existe un fundamento para dejarlas de lado en la formación de los nombres científicos (Filgueiras, 1997). Las reglas del biocódigo en relación con el latín son incongruentes: proponen no usar obligatoriamente las diagnosis en latín, conservar y proponer los nombres en latpín, sin embargo no tomando en cuenta la gramática latina.

Homonimia. Al contar con un solo código de nomenclatura biológica y considerar todos los nombres científicos de los seres vivos del planeta, los homónimos serán frecuentes. Se ha planteado que los problemas de homonimia entre dos reinos no pueden eliminarse sin el rompimiento de la nomenclatura existente (Zijlstra, 1996). Sin embargo, otros taxónomos consideran que la eliminación de los homónimos entre los reinos producirá una gran cantidad de trabajo y de nombres innecesarios, por lo que sugieren que los homónimos entre taxa botánicos y zoológicos podrían eliminarse agregando tan solo un pequeño párrafo a los códigos existentes sin la necesidad de un nuevo código de nomenclatura biológica (Brummitt, 1996).

\section{Conclusiones}

La mayoría de los cambios propuestos en el biocódigo han generado gran controversia entre la comunidad taxonómica mundial, sobre todo entre los botánicos quienes han argumentado que aprobarlo representaría un retroceso de más de 200 años de trabajo (Brummitt, 1996).

Esta controversia, ha ocasionado que el biocódigo no se presente para su aprobación en el próximo Congreso Internacional de Botánica, en agosto de 1999, y que obviamente no regule la bionomenclatura a partir del año 2000, como se había planteado originalmente. Sin embargo, dos reglas incluídas en el biocódigo, entre otras propuestas, serán consideradas en este congreso. Estas son el registro obligatorio de nuevos nombres científicos y la elaboración de listas de nombres de uso actual (Borgen et al., 1998; Greuter, 1998b; Greuter y Hawksworth, 1999). Su aprobación será crítica para avanzar en el establecimiento del biocódigo, aunque su aceptación parece difícil por las discusiones de grupos de botánicos vertidas en diferentes foros como Taxon y en páginas de internet de grupos de taxónomos vegetales (e.g. "International Association for Plant Taxonomy Alternative Website" y "Missouri Botanic Garden: Registration of Plant Names").

En resumen, los argumentos a favor del biocódigo se centran sobre la adopción de reglas que gobier- 
nen los nombres de todos los organismos y la creación de nuevos términos, lo que hará la nomenclatura más simple en el futuro y facilitará la comunicación entre los interesados, independientemente de los organismos con que trabajen.

Los argumentos en contra del biocódigo son principalmente en las listas de nombres de uso actual y el registro de nombres nuevos, ya que implicaría la creación de una comisión que presupone una burocracia, que podría poner en peligro la validación de los nombres científicos.

Por todos los puntos expresados, los autores de este artículo pensamos que el biocódigo es aún complejo, incompleto y controversial. Entre los puntos más importantes, que se requieren aún detallar están: 1] la congruencia del uso del latín, tanto en las diagnosis como en los nombres científicos; 2] el análisis de si es necesaria una burocracia para el registro y formación de listas de nombres científicos y 3] la forma de enienda al biocódigo, sin que éstas puedan hacerse únicamente por el Comité Internacional de Bionomenclatura.

Finalmente, pese a que muchas de las discusiones hacen referencia a los problemas que surgirían con la creación de un nuevo código, es de suma importancia que los taxónomos puedan resolverlos de forma conjunta y por consenso.

\section{Agradecimientos}

A los Drs. Gerrit Davidse, Tarciso S. Filgueiras, Francisco Lorea y Jerzy Rzedowski por sus acertadas sugerencias. Al Dr. Rafael Lira en la obtención de literatura.

\section{Literatura citada}

Anónimo. 1867. Laws of botanical nomenclature adopted by the International Botanical Congress held at Paris in August, 1867.

Barneby R. C. 1990. Commentary upon killing the holy cow. Taxon 39:241.

Borgen L., Greuter W., Hawksworth D. L., Nicolson D. H. y Zimmer B. 1998. Proposals to implement mandatory registration of new names. Taxon 47:899-904.

Brummitt R.K. 1996. Quite happy with the present code, thank you. En: Reveal J. L., Edr. Proceedings of a mini-simposium on biological nomenclature in the 21 st century. University of Maryland: http://www.life.umd.edu/bees/ 96 sym.html

Brummitt R. K. y Powell C. E. Edrs. 1992. Authors of Plant Names. Royal Botanic Gardens, Kew.

Craven L. A. 1997. Proposals to substitute English in place of Latin description or diagnosis as a requirement for valid publication. Taxon 46:809-810.

Delprete P. 1996. Biological Nomeclature. En: Reveal J. L. Edr. Proceedings of a mini-simposium on biological nomenclature in the 21st century. University of Maryland: http:/ /www.life.umd.edu/bees/96sym.html

Filgueiras T. S. 1997. In defense of Latin for describing new taxa. Taxon 46:747-749.

Greuter W., Barrie F. R., Burdet H. M., Chaloner W. G., Demoulin V., Hawksworth D. L., Jorgensen P. M., Nicolson D. H., Silva P. C., Trehane P. y McNeill J. Edrs. 1995. International Code of Botanical Nomenclature. Regnum Vegetabile 129.

Greuter W. 1996. On a new BioCode, harmony, and expedency. Taxon 45:291-294.

Greuter W. 1998a. Proposal to spell out a new principle in the Code: a homage to Candolle. Taxon 47:905.

Greuter W. 1998b. Two proposals on art. 15, and report of the standing committee on lists of names in current use. Taxon 47:895-898.

Greuter W., Hawksworth D. L., McNeill J., Mayo M. A., Minelli A., Sneath P. H. A., Tindall B. J., Trehane P. y Tubbs P. 1998. Draft BioCode (1997): the prospective international rules for the scientific names of organisms. Taxon 47:127-150.

Greuter W. y Hawksworth D. L. 1999. Synopsis of proposals on botanical nomenclature- St Louis 1999. A review of the proposals concerning the International Code of Botanical Nomenclature submitted to the XVI International Botanical Congress. Taxon 48:69-128.

Hawksworth D. L. 1995. Steps along the road to a harmonized bionomenclature. Taxon 44:447-456.

Holmgren P. K., Holmgren N. H. y Barnett I. 1990. Index herbariorum, Part I. The herbaria of the world, ed. 6. Regnum Vegetabile 92.

IUBS. 1994a. Biology International, Special Volume 30

IUBS. 1994b. A Draft Glossary of Terms used in Bionomenclature. IUBS, Monograph 9.

Lapage S. P., Sneath P. H. A., Lessel E. F., Skerman V. B. D., Seeliger H. P. R. y Clark W.A. Edrs. 1992. International Code of Nomenclature of Bacteria. Washington, D.C.

Linneo C. (Carl von Linné). 1753. Species Plantarum. Ed. 1.

Linneo C. (Carl von Linné). 1754, 1764. Genera plantarum. Ecls. 5, 6 .

McNeill J. 1996a. General introduction to the draft BioCode. Royal Ontario Museum: http://www.rom.on.ca/ebuff/ intro.htm.

McNeill J. 1996b. The BioCode: integrated biological nomenclature for the 21 st century? En: Reveal J. L. Edr. Proceedings of a mini-simposium on biological nomenclature in the 21st century. University of Maryland: http:// www.life.umd.edu/bees/96sym.html

McNeill J. 1997. Latin, the renaissance lingua franca, and english, the 20th century language of science: their role in biotaxonomy. Taxon 46:751-757. 
Murphy F. A., Fauquet C. M., Bishop D. H. L., Ghabrial S. A., Jarvis A. W., Martelli G. P., Mayo M. A. y Summers M. D. 1995. Virus taxonomy- the classification and nomenclature of viruses. Sixth Report of the International Committee on Taxonomy of Viruses.

Nicolson D. H. 1991. A history of botanical nomenclature. Annals of Missouri Botanical Garden 78:32-56.

Orchard A. E., Anderson W. R., Gilbert M. G., Sebsebe D., Stearn W. T. y Voss. E. G. 1996. Harmonized bionomenclature - a recipe for disharmony. Taxon 45:287-290.

Reveal J. L. 1996. Solutions for biological nomenclature. En: Reveal J. L., Edr. Proceedings of a mini-simposium on biological nomenclature in the 21st century. University of Maryland: http://www.life.umd.edu/bees/96sym.html

Ride W. D. L., Sabrosky C. W., Bernardi G. y Melville R.V. Edrs. 1985. International code of Zoological Nomenclature. ed. 3. London
Strother J. L. 1995. The emperors' new Code. Taxon 44:83. Trehane P., Brickell C. D., Baum B. R., Hetterscheid W. L. A., Leslie A. C., McNeill J., Spongberg S. A. y Vrugtman F. Edrs.). 1995. The International Code of Nomenclature for cultivated plants-1995. Regnum Vegetabile 133.

Turland N. J. y Davidse G. 1998. Registration of plant names: undesirable, unnecessary, and unworkable. Taxon 47:957.

Wilson K. L. 1997. Registration as a positive step. Taxon 46:811.

Zijlstra G. 1996. Two codes in a dual system? No thanks. En: Reveal J. L. Edr. Proceedings of a mini-simposium on biological nomenclature in the 21st century. University of Maryland: http://www.life.umd.edu/bees/96sym.html 